\begin{tabular}{|c|c|c|c|c|}
\hline $\begin{array}{c}\text { Jurnal Penelitian \& } \\
\text { PPM }\end{array}$ & ISSN: 2442-448X & Vol 4, No: 2 & Hal: $129-389$ & Juli 2017 \\
\hline
\end{tabular}

\title{
JARINGAN SOSIAL MASYARAKAT DI RING 1 TERMINAL BBM PERTAMINA PADALARANG
}

\author{
OLEH: \\ DR. MUHAMMAD FEDRYANSYAH, S.SOS., M.SI. \\ 1. Departemen Kesejahteraan Sosial FISIP Universitas Padjadjaran \\ muhammad.fedryansyah@unpad.ac.id
}

\begin{abstract}
ABSTRAK
Pelaksanaan program Corporate Social Responsibility (CSR) yang efektif adalah dengan melibatkan masyarakat yang menjadi sasaran program. Pelibatan tersebut dapat dilakukan ketika perusahaan mampu memetakan jaringan sosial yang ada di masyarakat. Jaringan sosial juga disebut sebagai para stakeholders yang berhubungan di masyarakat. Salah satu perusahaan yang menjalankan program CSR adalah Terminal BBM Pertamina Padalarang. Penelitian ini diarahkan untuk menjabarkan tentang pemetaan jaringan sosial masyarakat yang berada di Ring 1 Terminal BBM Pertamina Padalarang. Metode yang digunakan dalam penelitian ini adalah kualitatif dengan melakukan analisis berdasarkan interpretasi dari data primer maupun sekunder. Adapun gambaran mengenai jaringan sosial masyarakat di Ring 1 Terminal BBM Pertamina Padalarang dapat dilihat dari identifikasi stakeholders, dan hubungan antar stakeholders.
\end{abstract}

Kata kunci : corporate social responsibility, stakeholders

\begin{abstract}
Community involvement will assist in the effective implementation of CSR programs. It could be done when the company is able to find the existing social network in the community. Social networks are also referred to all the stakeholder in the community. One of the companies that run the CSR program is Terminal BBM Pertamina Padalarang. This research is directed to describe the mapping of social network of community in Ring 1 Terminal BBM Pertamina Padalarang. The method used in this research is qualitative by doing analysis based on interpretation from primary and secondary data. The description of the social network in Ring 1 Terminal BBM Pertamina Padalarang can be seen from the identification of stakeholders and relationships among stakeholders.
\end{abstract}

Key words : corporate social responsibility, stakeholders

\section{Pendahuluan}

Perusahaan tidak hanya sebagai badan usaha yang hanya berorientasi mencari keuntungan untuk turut mensejahterakan masyarakat di sekitarnya (people), serta wajib peduli terhadap lingkungan hidup untuk keberlanjutan keragaman hayati (planet) (Elkington, 2007). Berdasarkan hal tersebut, perusahaan tidak dapat mengesampingkan kondisi lingkungan sekitarnya. Sebuah perusahaan wajib untuk melakukan tanggung jawab sosial terhadap masyarakat sekitar dan lingkungannya. Tanggung jawab sosial perusahaan yang dikenal sebagai corporate social responsibility (CSR) menjadi suatu kewajiban bagi seluruh pelaku usaha di seluruh dunia. 
World Business Council for Sustainable Development mendefinisikan CSR sebagai komitmen berkelanjutan oleh dunia usaha untuk bertindak sesuai etika dan berkontribusi kepada pembangunan ekonomi sambil meningkatkan kualitas hidup dari tenaga kerja dan keluarganya, maupun komunitas lokal dan masyarakat secara keseluruhan (Galbreth, 2006). Berdasarkan definisi tersebut terlihat bahwa mensejahterakan masyarakat sekitar sebagai sebuah etika yang harus dijalankan oleh perusahaan. Kondisi dikarenakan keberadaan perusahaan dalam suatu wilayah akan menyebabkan perubahan pada komunitas lokal maupun masyarakat secara keseluruhan. Dengan demikian perusahaan mempunyai tanggung jawab untuk membantu komunitas lokal maupun masyarakat dalam mengatasi perubahan sosial yang terjadi sehingga kualitas hidup dari komunitas lokal maupun masyarakat dapat meningkat.

Salah satu upaya yang dilakukan perusahaan adalah dengan melaksanakan program CSR yang sesuai dengan kebutuhan masyarakat. Dengan demikian, pelibatan masyarakat dalam perancangan dan pelaksanaan program CSR menjadi syarat yang mutlak. Pelibatan masyarakat dapat dilakukan ketika perusahaan dapat mengidentifikasi pihak-pihak atau aktor-aktor di masyarakat yang bisa diajak bekerja sama dalam menjalankan program CSR.

Identifikasi pihak-pihak atau aktor-aktor terkait itu dapat disebut pula sebagai identifikasi stakeholders. Pengidentifikasian stakeholders tersebut dapat dilakukan melalui pemetaan sosial di masyarakat sasaran. Pemetaan sosial menjadi langkah awal dalam rangkaian pelaksanaan program CSR yang dilakukan oleh perusahaan.

Salah satu perusahaan yang melakukan pemetaan sosial dengan menekankan pada identifikasi stakholders di masyarakat sekitar perusahaan atau Ring 1 perusahaan adalah Terminal BBM Pertamina Padalarang. Hasil kajian pemetaan sosial ini diarahkan sebagai dasar (baseline) dalam perumusan program yang sesuai dengan kebutuhan-kebutuhan dan potensi yang dimiliki oleh masyarakat.

Dalam kajian penelitian ini yang menjadi subjek penelitian adalah Desa Kertajaya. Desa Kertajaya merupakan desa yang berada tepat di wilayah Ring 1 dari TBBM Padalarang tepatnya berada di Dusun 1 dan Dusun 2. Desa Kertajaya merupakan hasil pemekaran dari Desa Simpang secara formal menjadi desa tersendiri sejak tahun 1976. Secara geografis terletak $3 \mathrm{~km}$ disebelah selatan Kantor
Pemda Kabupaten Bandung Barat (Ngamprah) dengan luas wilayah 371,555 Ha juga menjadi pintu masuk antara wilayah barat Ibu kota negara menuju Ibu Kota Provinsi Jawa Barat yaitu Bandung. Desa Kertajaya terdiri dari 5 dusun dengan 22 Rukun Warga dan 86 Rukun tetangga.

Kajian ini akan memusatkan perhatian pada jaringan stakeholders masyarakat Ring 1 Terminal BBM Pertamina Padalarang.

\section{Metode Penelitian}

Penelitian ini bermaksud untuk mengkaji jaringan stakeholders masyarakat Ring 1 Terminal BBM Pertamina Padalarang. Untuk mendapatkan gambaran mengenai jaringan stakeholders di masyarakat tersebut, maka dalam penelitian ini digunakan metode deskriptif dan pendekatan kualitatif.

Pengumpulan data dalam kegiatan ini terdiri dari data sekunder dan data primer. Data sekunder diarahkan kepada dokumen-dokumen terkait dengan gambaran umum masyarakat di Kecamatan Padalarang Kabupaten Bandung Barat. Sedangkan data primer diarahkan untuk menggali informasi secara langsung di lapangan terkait dengan jaringan stakeholders, yang dilakukan dengan cara menggunakan wawancara mendalam serta melakukan Focus Group Discussion. Penelitian ini melibatkan 30 orang informan yang dipandang memiliki pengetahuan dan informasi mengenai kondisi di desa-desa yang ada di Kecamatan Padalarang. Informan tersebut terdiri dari aparat pemerintahan desa, tokoh masyarakat, serta masyarakat awam yang ada di setiap desa.

\section{Identifikasi Stakeholders Masyarakat Ring 1 Terminal BBM Pertamina Padalarang}

Pada umumnya stakeholders diartikan sebagai orang yang mengambil peran aktif dalam setiap kegiatan atau orang yang memiliki pengaruh yang signifikan bagi masyarakat. Terkait dengan stakeholders yang terdapat di masyarakat, maka tidak akan terlepas dari sebuah hubungan antar stakeholder yang ada. Pada umumnya setiap stakeholders memiliki kewenangan, tujuan, dan tingkat kepentingan yang berbeda-beda. Adapun stakeholders yang terkait hasil dari pemetaan 
sosial di wilayah Desa Kertajaya yaitu pemerintah, pelaku industri (pihak swasta), dan masyarakat.

Stakeholder yang berada di tingkat pemerintahan yakni dari tingkat pemerintahan desa meliputi Kepala Desa, Ibu-ibu PKK, Kepala Karang Taruna, Kepala BPD, dan Kepala Poskesdes. Peran aparat pemerintahan desa masih memiliki kewenangan dan menjadi panutan masyarakat. Dalam hal ini masyarakat melihat sosok aparat pemerintahan desa yang terkesan mengayomi masyarakat. Bapak Fauzi selaku Kepala Desa Kertajaya adalah bagian dari aparat pemerintahan desa yang peranannya menjadi penggerak cukup vital dalam pengelolaan Desa Kertajaya. Beliau terpilih menjadi kepala desa selama dua periode dengan lumbung suara yang cukup signifikan menjadi bekal untuk lolos di putaran kedua. Hal ini dikarenakan Pak Fauzi menjadi sosok yang kental dengan programprogram yang berhubungan dengan kemaslahatan bersama dan sangat mendengarkan keluh-kesah masyarakat melalui interaksi formal baik di dalam rapat dan nonformal yakni turun langsung ke lapangan. Selain itu terdapat perangkat desa yang ikut serta membantu program yang diusung Pak Fauzi dalam rangka pembangunan Desa Kertajaya yaitu diantaranya Ibu Lina selaku ketua dari penggerak PKK untuk memberdayakan ibu-ibu di Desa Kertajaya, kemudian Bapak Odong selaku Ketua Karang Taruna yang memiliki kewenangan untuk mampu mengayomi kaum lelaki khususnya remaja, dan Bidan Sari selaku Kepala Poskesdes.

Selain dari pihak pemerintah, pihak swasta turut memberikan andil bagi pembangunan di Desa Kertajaya. Pihak swasta diikutsertakan dalam rangka pembangunan di Desa Kertajaya baik dari segi fisik maupun no-fisik, sebab pembangunan di sebuah wilayah merupakan tanggung jawab semua pihak yang tinggal di wilayah tersebut.

Hadirnya stakeholders swasta yang diwakili dari pihak pelaku industri yang berdiri di Desa Kertajaya seperti Terminal BBM Pertamina Padalarang yang berada di Dusun 2 sejak tahun 1990, SPBE \& Perumahan Kotabali yang berada di Dusun 3,
Indofood, Kotabaru Parahyangan, dan Chombipar 1985 yang berada di Dusun 5, serta Vitabiotik plus PT Belaputra yang berada di Dusun 4. Hadirnya pelaku industri di wilayah Desa Kertajaya bukan tanpa alasan, hal ini ditunjang dengan akses jalan segitiga emas. Dalam hal ini lokasi wilayah Desa Kertajaya merupakan akses yang paling terdekat untuk ditempuh menggunakan jalur Toll Purbaleunyi, selain itu berdekatan dengan jalan raya utama yang aksesnya dengan mudah untuk mencapai ke berbagai wilayah seperti wilayah seperti Cimahi, Lembang, Bandung Barat, Purwakarta, dan Cianjur. Dengan kondisi wilayah yang sangat strategis mampu menarik pelaku industri untuk membangun pabrik di wilayah Kecamatan Padalarang khususnya di Desa Kertajaya.

Saat ini, hampir keseluruhan kegiatan pembangunan di Desa Kertajaya menerapkan pendekatan partisipatif/gotong-royong yang mengikutsertakan seluruh elemen masyarakat. Stakeholder dari tokoh masyarakat Kertajaya biasanya diperankan oleh setiap Kepala Dusun seperti Pak Aco selaku Kadus 1, Pak Dadang Kadus 2, Pak Agus Kadus 3, Pak Acang Kadus 4, dan Pak $\mathrm{Hj}$. Otong Kadus 5. Selain kepala dusun, juga terdapat tokoh lain di bidangnya masing-masing seperti Bapak Drs. Dodi selaku tokoh pendidikan, Pak Ust. Yasir selaku tokoh agama sekaligus Ketua MUI, dan Pak Odong selaku tokoh pemuda. Peran tokoh masyarakat bagi masyarakat Desa Kertajaya sangat dibutuhkan, terlebih tokoh masyarakat dianggap mampu menjadi perwakilan aspirasi dari masyarakat dan penengah dalam penyelesaian masalah di bidang kesehatan, pendidikan, dan infrastruktur yang telah disusun oleh Pak Suherman selaku Ketua LPMD. Dalam hal ini tokoh masyarakat menjadi yang paling dituakan dalam konteks hubungan internal dan eksternal dengan mengacu pada semua peraturan yang berlaku, serta menjunjung etika dan tata nilai atau norma di masyarakat.

Di bawah ini merupakan data stakeholder yang merupakan tokoh masyarakat di desa Kertajaya: 


\begin{tabular}{|c|c|c|c|c|}
\hline $\begin{array}{c}\text { Jurnal Penelitian \& } \\
\text { PPM }\end{array}$ & ISSN: 2442-448X & Vol 4, No: 2 & Hal: $129-389$ & Juli 2017 \\
\hline
\end{tabular}

Tabel 1

Stakeholders Masyarakat Ring 1

Terminal BBM Pertamina Padalarang

\begin{tabular}{|c|c|c|c|}
\hline NO & Nama & Posisi & Keterangan \\
\hline 1 & Pak Fauzi & Kepala Desa & Terpilih 2 periode berturut-turut \\
\hline 2 & Ibu Lina & $\begin{array}{ll}\text { Tokoh } & \text { PKK/Istri } \\
\text { Kades } & \end{array}$ & $\begin{array}{l}\text { Aktif dalam kegiatan PKK dan Posyandu, sangat } \\
\text { memahami kebutuhan ibu dan balita di } \\
\text { wilayahnya. Memiliki kemampuan untuk } \\
\text { mengajak perempuan lain untuk berpartisipasi }\end{array}$ \\
\hline 3 & Pak Aco & Kepala Dusun 1 & $\begin{array}{l}\text { Memiliki pemahaman mengenai wilayahnya } \\
\text { secara menyeluruh }\end{array}$ \\
\hline 4 & Pak Dadang & Kepala Dusun 2 & $\begin{array}{l}\text { Memiliki pemahaman mengenai wilayahnya } \\
\text { secara menyeluruh }\end{array}$ \\
\hline 5 & Pak Agus & Kepala Dusun 3 & $\begin{array}{l}\text { Memiliki pemahaman mengenai wilayahnya } \\
\text { secara menyeluruh }\end{array}$ \\
\hline 6 & Pak Acang & Kepala Dusun 4 & $\begin{array}{l}\text { Memiliki pemahaman mengenai wilayahnya } \\
\text { secara menyeluruh }\end{array}$ \\
\hline 7 & Pak Otong & Kepala Dusun 5 & $\begin{array}{l}\text { Memiliki pemahaman mengenai wilayahnya } \\
\text { secara menyeluruh }\end{array}$ \\
\hline 8 & Pak Dodi & Tokoh Pendidikan & $\begin{array}{l}\text { Tokoh yang memahami perkembangan } \\
\text { pendidikan di kertaJaya, berprofesi sebagai } \\
\text { pendidik. }\end{array}$ \\
\hline 9 & Ustadz Yasir & Tokoh Agama & Tokoh MUI, disegani oleh masyarakat \\
\hline 10 & Pak Odong & Tokoh Pemuda & $\begin{array}{l}\text { Dapat mengajak pemuda untuk berpartisipasi, } \\
\text { memiliki jiwa kepemimpinan, disegani kaum } \\
\text { muda maupun Tua }\end{array}$ \\
\hline 11 & $\begin{array}{l}\text { Pak } \\
\text { Suherman }\end{array}$ & Ketua LPMD & $\begin{array}{l}\text { Mengetahui informasi mengenai permasalahan } \\
\text { dan potensi ekonomi desa. }\end{array}$ \\
\hline
\end{tabular}

\section{Hubungan Antar Stakeholders Masyarakat Ring 1 Terminal BBM Pertamina Padalarang}

Hubungan antar stakeholder dilihat dari kerjasama yang dilakukan diantara para stakeholder. Adapun bentuk kerja sama tersebut yaitu berupa penyerapan tenaga kerja dan tanggung jawab perusahaan atau disebut dengan CSR. Pada bantuan berupa penyerapan tenaga kerja, dalam hal ini PT. Indofood memberikan kesempatan kepada masyarakat Desa Kertajaya untuk bergabung menjadi pegawai per 3 bulan atau 6 bulan sekali diadakan perputaran karyawan dan pemberian PMT untuk bayi yang memiliki bobot di bawah standar. Bantuan tersebut tidak selalu dalam bentuk infrastruktur fisik namun juga nonfisik yang berupa pelatihan-pelatihan yang bertujuan dalam rangka pengembangan kapasitas. Adapun bentuk CSR yang pernah dilakukan oleh pelaku industri khususnya Terminal BBM Pertamina Padalarang yaitu pembangunan poskesdes lengkap dengan fasilitas yang sudah cukup memadai untuk bayi dan orang tua. Hal ini disambut dengan sangat antusias oleh masyarakat Desa Kertajaya, sebab kini masyarakat memiliki poskesdes yang layak dengan tenaga medis yaitu kader-kader PKK yang sudah diberikan pelatihan oleh Pertamina sejak tahun 2011 sehingga menambah kualitas pelayanan kesehatan. 
Selain hubungan yang baik antara desa dengan pihak industri, terdapat hubungan yang harmonis antara aparatur desa dengan stakeholders yang bergerak di bidang pendidikan dalam hal ini sekolah. Hasil pemetaan memberikan informasi bahwa pada saat pembangunan posyandu yang terdapat di RW 13 menemui sedikit hambatan yaitu kurangnya dana pembangunan yang diberikan oleh PNPM. Saat itu dana hanya mampu diberikan PNPM sebesar 26 juta, tapi besar pengeluaran yang di prediksi sebesar 45 jutaan. Hal ini pihak sekolah khususnya SMK Kertajaya memberikan lahan untuk membangun posyandu dan juga bantuan kayu balok, sedangkan sisanya hasil dari swadaya masyarakat. Dari hal ini dapat memberikan gambaran bahwa antar pemangku kepentingan dan antar masyarakat metode pembangunan partisipatif masih dilakukan hingga saat ini dan terkesan harmonis.

Hubungan baik juga terjalin antar warga, hal tersebut terlihat dari kepatuhan dan toleransi masyarakat dengan berbagai stakeholders yang ada. Seperti dalam bidang keagamaan, meskipun tidak sepenuhnya masyarakat Desa Kertajaya umat muslim namun dengan bekal sifat gotong royong dan toleransi antar umat beragama terbangun ikatan hubungan yang baik mengenai kebutuhan, peringatan besar agama, dan pembangunan fasilitas keagamaan. Selain itu keharmonisan tersebut dapat terjaga berkat kegiatan-kegiatan yang melibatkan banyak massa seperti olahraga, pengajian, kerja bakti, dan kesenian.

Dengan demikian, hubungan antar stakeholders yang ada di masyarakat yang semula tidak aktif (inactive), menjadi reakif (reactive), kemudian berubah lagi menjadi proaktif (proactive), dan akhirnya menjadi interaktif (interactive) seiring dengan berjalannya waktu. Hal tersebut dapat terwujud dengan adanya hubungan yang baik (simbiosis mutualisme) antara masyarakat asli Kertajaya dengan pelaku industri, terlebih dari tidak adanya konflik dan keluhan dari masyarakat dengan adanya industri di wilayah pemukiman. Hubungan yang harmonis dapat memberikan dampak yang positif untuk keberlangsungan hidup dan pembangunan masyarakat serta menjaga citra industri yang baik di mata masyarakat.

\section{Penutup}

Gambaran mengenai stakeholders masyarakat Ring 1 Terminal BBM Pertamina Padalarang dapat dilihat dari identifikasi stakeholders dan hubungan antar stakeholders. Stakehoders yang terdapat di masyarakat Ring 1 Terminal BBM Pertamina Padalarang dapat dibagi menjadi tiga bagian yaitu pemerintah, swasta dan masyararakat. Pemerintah dalam hal ini adalah pemerintah desa, di mana tokoh yang memiliki pengaruh cukup besar adalah Kepala Desa dan Ketua BPD serta Ketua Karang taruna dan Ketua PKK. Sedangkan untuk stakeholder swasta adalah pihak perusahan dan industri di sekitar Desa Kertajaya. Serta tokoh masyarakat yang berpengaruh adalah masyarakat yang memiliki pengaruh cukup besar dalam kehidupan bermasyarakat Desa Kertajaya, tokohtokoh tersebut adalah Kepala Dusun, Tokoh Pendidikan, Tokoh Agama, dan orang yang dituakan.

Stakeholders tersebut saling bahu-membahu untuk turut serta dalam pembangunan Desa Kertajaya. Hubungan antar stakeholders yang ada di masyarakat yang semula tidak aktif (inactive), menjadi reaktif (reactive), kemudian berubah lagi menjadi proaktif (proactive), dan akhirnya menjadi interaktif (interactive) sehingga memberikan dampak yang positif untuk keberlangsungan hidup dan pembangunan masyarakat.

\section{Daftar Pustaka}

Adamson, D. 2010. Community empowerment: Identifying The Barriers to "purposesful" Citizen Participation. International Journal of Sociology vol. $303 / 4,114-126$.

Adi, I. R. 2003. Empowerment, Community Development< and Community Intervention. Jakarta: FE-Universitas Indonesia.

- 2003. Pemberdayaan, Pengembangan Masyarakat< dan Intervensi Komunitas. Jakarta: LP.FE- Universitas Indonesia.

.2007. Perencanaan partisipatoris berbasis aset komunitas: dari pemikiran menuju penerapan. Jakarta: FISIP UI Press.

Alfitri. 2010. Program Community Development Perusahaan Migas Dalam Penguatan Modal Sosial. Bandung :Pascasarjana UNPAD

Amaeshi, K. and Adi, A. B. C. 2007. Reconstructing the Corporate Social Responsibility Construct in Utlish. Business Ethics: A European Review vol. 16, pp:3-18 


\begin{tabular}{|c|c|c|c|c|}
\hline $\begin{array}{c}\text { Jurnal Penelitian \& } \\
\text { PPM }\end{array}$ & ISSN: 2442-448X & Vol 4, No: 2 & Hal: $129-389$ & Juli 2017 \\
\hline
\end{tabular}

Babbie, A. R. 2005. Research Methods for Social Work. Belmont: Thomson Brooks/Cole.

Bryman, A. 2005. Integrating Quantitative and Qualitative Research: Prospects and Limits. Economic and Social Research Council

Butcher, H., Banks, S., Henderson, P., Robertson, J. 2003. Managing The Community Practice : Principles, Policies, and programmes. Bristol : Policy Press

Cary, L.J. 1970. Community Development As a Process. Columbia: University of Missouri Press

Elkington, J. 1997. Cannibals with Forks: The Triple Bottom Line of 21st Century. Philadelphia: New Society.

Eweje, G. 2007. Multinational oil companies' CSR Initiatives in Nigeria. Managerial Law Vol. 49 , 218-235.

Fatah, L. 2008. The Impacts of Coal Mining on the Economy and Environment of South KAlimantan Province, Indonesia. Asean Economic Bulletin vol 25 , 85-98.

Frank den Hond, F.G. 2007. Managing CSR in Action; Talking, Doing, and Measuring. England: Ashgate Publishing Limited.

Frynas, J. G. 2009. Beyond orporate Soial Responsibility. New York: Cambridge University Press.

Garriga, Elisabet ., D. M. 2004. Corporate Social Responsibility Theories: Maping the Territory. Journal of Business Ethics vol $53,51-71$.
Griffin, A. 2008. Reputation Management "Gaining Control of Issues, Crises and CSR. London: Kogan Page.

Herbert J. Rubin, I. S. 1992. Community Organizing and Development 2nd Edition. New York: Macmillan Publishing Company.

Hirshland, M. J. 2006. Corporate SSocial responsibility and The Shaping of G. New York: Palgrave Macmillan.

Hopkins, M. 2007. Corporate Social Responsibility \& International Development; Is Business The Solution?. United Kingdom: Earthscan.

Ife, J. 2000. Community Development: Community-Based Alternatives in Age of Globalization. Melbourne: Longman.

Ife, Jim., F. T. 2007. Community Development : Communit-based alternatives in age of globalization. Melbourne: Longman.

Kapelus, P. 2002. Mining, Corporate Social Responsibility and the "Community" : The Case of Rio Tinto, Richard Bay Minerals and the Mbonambi. Journal of Business Ethics, 275-296.

Raharjo, ST. 2015. Assessment untuk Praktik Pekerjaan Sosial dan Kesejahteraan Sosial. Bandung: Unpad Press 2015. Dasar Pengetahuan Pekerjaan Sosial. Bandung: Unpad Press. 2015. Keterampilan Pekerjaan Sosial: Dasar-dasar. Bandung, Unpad Press. 